\title{
Can coffee consumption lower the risk of Alzheimer's disease and Parkinson's disease? A literature review
}

\author{
Regina Wierzejska
}

National Food and Nutrition Institute, Warsaw, Poland

Submitted: 21 April 2016

Accepted: 9 August 2016

Arch Med Sci 2017; 13, 3: 507-514

DOI: 10.5114/aoms.2016.63599

Copyright @ 2016 Termedia \& Banach

\begin{abstract}
In light of the fact that the number of elderly citizens in society is steadily increasing, the search for dietary factors which might prolong mental agility is growing in significance. Coffee, together with its main ingredient, caffeine, has been the focus of much attention from various researchers, as data on its beneficial effects on human health continue to accumulate. Most reports indicate that moderate coffee consumption may in fact lower the risk for common neurodegenerative conditions, i.e. Alzheimer's and Parkinson's diseases. Regardless, due to their complex pathogenesis as well as methodology of scientific research, the exact impact of coffee consumption remains to be fully elucidated. At present, it seems safe to inform the general public that coffee drinkers need not fear for their health. Possibly, in the future experts will recommend drinking coffee not only to satisfy individual taste preferences but also to decrease age-related mental deterioration.
\end{abstract}

Key words: coffee, dementia, Alzheimer's disease, Parkinson's disease.

\section{Introduction}

According to demographic statistics, numerous populations in various regions of the world have noted a steadily increasing lifespan over the last decades. In Poland, average life expectancy has risen by 17 years for males and 19 for females as compared to the 1950s (from 56 to 73 years and from 62 to 81 years, respectively) [1]. The data are undoubtedly optimistic, but it is important to bear in mind that increased lifespan and aging of society will result in higher rates of age-related disorders, including neurodegenerative diseases, e.g. Alzheimer's disease (AD) and Parkinson's disease (PD) [2-5]. Dementia, which develops in brain-degenerative diseases, has been estimated to affect approximately $10 \%$ of people $>65$ years of age, but the prevalence index doubles every 5 years. Also, experts emphasize that epidemiological data may be inconsistent due to variability in the diagnostic criteria [4]. Population aging is the reason why healthcare systems all over the world face the need to change and to increase their expenditures on elderly citizens [2, 5]. At present, due to a lack of effective therapies for neurodegenerative diseases, attempts are being made to discover their pathogenesis, including the impact of genetic and numerous environmental factors [6-12]. Their role might be proven by significant differences in the incidence of dementia in various regions of the world, e.g. only $17 \%$ in China but $43 \%$ in Germany among people $\geq 85$ years of age [13].

\author{
Corresponding author: \\ Regina Wierzejska PhD \\ National Food \\ and Nutrition Institute \\ 61/63 Powsińska St \\ 02-903 Warsaw, Poland \\ Phone: + 48225509747 \\ E-mail: rwierzejska@izz. \\ waw.pl
}


The etiology of neurodegenerative diseases remains to be fully elucidated with respect to both genetic and environmental factors [8, 14]. The literature emphasizes the need to expand the knowledge about dietary factors which might slow down the development of dementia [10, 1517]. The 2012 Nutritional Prevention of Cognitive Decline Congress enumerated coffee, tea, B group vitamins, omega-3 acids, and vitamin D among the beneficial factors. However, their postulated preventive effects require extensive studies $[2,18-20]$. In the case of AD and PD, fish, antioxidants, including polyphenols (especially regular consumption of wine) and curcumin are believed to be beneficial, while saturated fatty acids, high intake of cholesterol and calories promote disease development [11, 15, 17, 21-25]. The literature suggests that the significantly lower prevalence of neurodegenerative diseases in Asian countries may be the result of a better diet, i.e. large quantities of fruit and vegetables, as well as spices [23].

The article summarizes current literature reports about the effect of coffee consumption on the risk of some neurodegenerative disorders.

\section{Coffee and the risk of dementia}

Caffeine - a psychoactive and neurostimulating substance - is one of the main ingredients of coffee and is hypothesized to help maintain cognitive functions in the elderly [2, 26-29]. Regardless, studies on the correlation between the effect of natural sources of caffeine - coffee and tea - and the changes in age-related mental agility have reported conflicting results.

As far as a beneficial effect of coffee is concerned, a large multicenter cohort study from three European countries (Holland, Finland, Italy) in elderly men demonstrated that coffee consumption was associated with slower progression of dementia, measured over the course of 10 years. The most beneficial effect (4-fold lower decrease in cognitive functions) was observed in the group with moderate coffee intake ( 3 cups a day), and the least beneficial in the group with low and high coffee consumption [29]. Also, a positive impact of moderate (3-5 cups a day) coffee consumption in middle-aged people, resulting in a significant decrease (by $65 \%$ ) of dementia risk in the elderly, was reported by Finnish researchers after a 21-year-long period of observation, contrary to low consumption of coffee in that group [30]. In turn, a 4-year-long observational French study in women $>65$ years of age, who consumed $>3$ cups of coffee a day, revealed a significantly lower deterioration of speech and memory function as compared to women who consumed 1 cup of coffee a day or abstained. However, no such findings were reported in the group of men [31]. A ran- domized study on the applicability of caffeine to treat somnolence in PD patients also generated interesting results [32]. Apart from motor symptoms, sleep disorders are among the symptoms of the disease, and daytime somnolence is often the cause of patient exclusion from social life [32, 33]. In a study by Postuma et al. Parkinson patients with excessive daytime somnolence received 200-400 mg of caffeine for the course of 6 weeks. Although no cases of decreased sleepiness were observed, significant improvement in motor skills was noted in the study group receiving caffeine as compared to placebo controls [32].

Coffee consumption may also affect brain vascular dementia. The vascular system has a significant impact on maintenance of cognitive function [34]. Vascular dementia can be caused by two events that can occur in blood vessels. The first is stroke and the second is small vessel disease, although many people may have a mixture of causes. Stroke refers to brain damage that is permanent and results from interrupted blood supply to a specific part of the brain. Small vessel disease results from damage to blood vessels. The pathophysiology of small vessel disease is complex. The thickening of the blood vessel walls, atherosclerosis, is accompanied by hardening of vessel walls, which result in narrowing of the lumen of the vessel. These two events (stroke and small vessel disease) impair cerebral blood flow and contribute to neurodegenerative disorders [35, 36].

A study by Nakaguchi et al. conducted in Japan demonstrated that people who drink at least 3 cups of coffee per day had a lower incidence of silent brain infarction in middle age, which can prevent vascular dementia in older age [37]. A meta-analysis of prospective studies found that habitual coffee consumption may be weakly inversely associated with risk of stroke. The strongest significant association (17\% lower risk) was noted in the case of moderate coffee consumption (3-4 cups/day). The authors of that report also pointed out that in four studies the association between coffee consumption and stroke was similar for ischemic stroke and hemorrhagic stroke, but the results were statistically significant only for ischemic stroke [38].

In contrast to the abovementioned studies, numerous authors report a lack of beneficial effects of coffee consumption on lucidity. Long-term cohort studies by Mirza et al., in a group of over 4000 elderly people in Holland, found no correlation between coffee intake and the development of dementia [39]. Identical results were reported by yet another observational study in Holland, and those authors questioned the validity of encouraging consumption of caffeinated drinks to decrease age-related mental deterioration [40]. 
Other data questioning the link between coffee intake and dementia come from Finland, where a 28-year-long study on twins found no correlation between coffee consumption in middle age and the development of dementia in older age [9]. Finally, two recently published reports from a cohort study in China [41] and Japan [28] also detected no correlation between coffee intake and decreased cognitive function. Interestingly, these studies concluded that tea lowered the risk of deteriorated mental agility in the elderly by $70 \%$ due to daily consumption of green tea [28], and by $30 \%$ for black and red tea [41]. Interestingly, also Italian prospective studies generated important data and showed that mild changes in cognitive functions were less frequently observed in elderly people who consumed a small amount of coffee (1-2 cups a day), consumption of $>2$ cups of coffee had no effect, whereas increased coffee intake over the course of the study resulted in deterioration of cognitive functions [42].

In light of the conflicting data of single studies, it seems prudent to focus on the results of metaanalyses. Santos et al., in their meta-analysis of cohort and case-control studies, found a slightly beneficial trend between coffee intake and decreased risk for dementia. However, these authors emphasize that the number of well-designed studies is very low, not permitting unequivocal conclusions [43]. Also Arab et al. are of the opinion that coffee or tea consumption may limit the decrease in cognitive functions but, similarly to other authors, they also emphasize methodological limitations of the available studies [44]. Contrary to the abovementioned sources, Kim et al., in the latest meta-analysis of observational studies, concluded that they found no correlation between caffeine intake, in tea or coffee, and dementia [8]. Discrepancies in methodology between various studies include, among other things, different diagnostic criteria, e.g. Mini-Mental State Examination, Diagnostic and Statistical Manual of Mental Disorders - Third Edition, or only a telephone interview, which might have affected the results.

\section{Coffee versus Alzheimer's disease}

Alzheimer's disease is the most prevalent neurodegenerative disease $[8,17,43]$. It has been estimated to constitute $50-70 \%$ of all cases of degenerative brain diseases [4, 12]. According to Wyka, it affects $5-10 \%$ of people $>65$ years of age and almost $50 \%$ of patients $>80$ [17]. Przysławski and Stelmach estimate that in Poland AD is diagnosed in 2.3-3.5\% of individuals between 65 and 84 years of age, with higher incidence among women than men [22]. Accumulation of $\beta$-amyloid, a protein which surrounds neurons and impairs absorption of nutrients and oxygen from blood vessels, plays a key role in the pathogenesis of the disease $[4,7,45]$. Thus, AD therapy aims to lower the level of that protein by inhibition of the enzyme activity generating amyloid production [7, 45]. In the future, the assay of $\beta$-amyloid in cerebrospinal fluid may be used in standard management to diagnose preclinical stages of the disease, i.e. the phase of mild cognitive impairment [46].

According to the literature, coffee consumption is hypothesized to be one of the possible preventive measures, which is based on the promising results of studies on animal models $[33,44]$. Arendash and Cao demonstrated that caffeine intake in mice - from young to old age - lowers the concentration of this neurotoxic peptide [47]. Thus, these authors concluded that caffeine consumed in moderation (the human equivalent of $500 \mathrm{mg}$ of caffeine or 5 cups of coffee a day) may protect against the development of $A D$ or may be used in its therapy [47].

A 2007 quantitative review of observational studies demonstrated a new, positive effect of coffee consumption on lowering the risk for AD approximately by $30 \%$ as compared to non-coffee consumers [48]. A 2010 review of longitudinal epidemiological studies suggested that daily intake of 3-5 cups of coffee in middle age may lower the risk of the disease by $64 \%$ as compared to lower amounts of coffee [6]. Two meta-analyses of cohort and case-control studies, from 2010 and 2015, also reported an inverse correlation between disease incidence and coffee/caffeine consumption $[43,49]$. Furthermore, a review of the literature on the effects of various environmental reasons for the development of $A D$ indicated a beneficial influence of coffee intake [14]. However, most authors emphasize a great number of methodological differences, which renders unequivocal conclusions difficult. One of the main limitations is a lack of accurate data on the duration of coffee intake among the studied populations. As a result, it is challenging to establish at what age coffee might start to exhibit its positive effect [43, 48]. The amounts of coffee, described as 'low', 'moderate', or 'high' in various sources [39, 42], and of caffeine in a cup, which might be anything between 36 and $220 \mathrm{mg}$, constitute yet another difference $[8,50]$.

\section{Coffee versus Parkinson's disease}

The incidence of PD in the general population has been estimated at $0.15-0.3 \%[7,51]$, increasing dramatically with age $(1.7-2.2 \%$ in people over 65 [52], and 4\% in the oldest age group [51]). According to Gawet and Potulska-Chromik, mean age at onset is 58 years [7]. The etiology of PD remains to be fully elucidated. As in the case of $A D$, genetic as well as environmental factors are taken into consideration [25]. 
The first reports about coffee consumption and the risk of PD were published in the 1970s [53]. Since then, numerous authors have investigated coffee as a potentially protective factor. Ascherio et al. demonstrated that men who drink at least 1 cup of coffee a day are at a lower risk for PD mortality as compared to non-coffee consumers. No such correlation was found in females, possibly as the result of hormone replacement therapy, which inhibits caffeine metabolism. Nevertheless, other prospective cohort studies of these authors reported an effect in women as well. The lowest risk for disease was associated with daily consumption of 1-3 cups of coffee [54]. Ross et al. conducted an observational study exclusively among men and demonstrated a dose-dependent positive effect of coffee consumption. Male non-coffee drinkers were at a 3-5-fold higher risk of developing $\mathrm{PD}$ as compared to men who consumed at least $800 \mathrm{ml}$ of coffee daily [55]. A correlation between coffee intake and disease development was also confirmed by studies in Parkinson patients only. Coffee drinkers developed the disease 8 years later than did non-coffee drinkers (mean age at onset 72 and 64 years, respectively) [56]. Despite the confirmed link, these authors suggest that coffee may be indirectly correlated with disease development, and that a complex interplay of numerous factors plays the decisive role. A cohort study from Finland in a population aged $50-79$, conducted over a period of 22 years, demonstrated that the highest consumption of coffee was associated with the lowest risk of the disease (74\% lower than for non-drinkers) [25]. However, a positive link between coffee intake and PD has not been confirmed by many clinical control trials, including the studies by Morano et al. [57], Checkoway et al. [58], and Jiménez-Jiménez et al. [59]. Also, no correlation was found between coffee consumption and mild changes typical for PD (i.e. tremor, $a b-$ normal posture and gait) in elderly people without diagnosed neurological diseases [60].

Joint studies offer more valid and general conclusions. A meta-analysis of cohort and case-control studies by Hernán et al., including reports published between 1966 and 2002, revealed a strong correlation between coffee consumption and the incidence of PD. Coffee drinkers were at a $30 \%$ lower risk of the disease as compared to non-drinkers [61], which is consistent with the latest meta-analysis from 2014 and the conclusion that the strongest positive effect (28\% lower risk) was observed for the daily intake of 3 cups of coffee [52]. Additionally, that analysis demonstrates a linearly dependent correlation between caffeine dose and risk for disease. Daily increase of caffeine consumption by $200 \mathrm{mg}$ resulted in a $17 \%$ lower risk for disease. Regardless, many authors emphasize the possibility that other factors might interfere with the correlation, e.g. smoking, which is associated with lower risk of the disease, whereas smokers tend to drink more coffee than non-smokers [9, 52, 62, 63]. Also, a meta-analysis of epidemiological studies by Costa et al. generated optimistic conclusions. According to these authors, caffeine lowered the risk of PD in a linear, dose-dependent manner. Moderate coffee consumption (300 $\mathrm{mg}$ a day) lowers the risk of PD disease by $24 \%$ [64].

\section{Coffee: a possible mechanism of action}

Explaining the widely reported link between coffee intake and the incidence of neurodegenerative diseases remains a considerable challenge. So far, none of the numerous hypotheses has been confirmed or rejected. Coffee contains many different components, mostly caffeine, polyphenol, trigonelline, niacin, potassium, diterpenes, and acrylamide $[6,8,62,65,66]$. Figure 1 presents a possible mechanism of the impact of coffee on the risk for neurodegenerative diseases [6, 66-79].

Most researchers focus their attention on caffeine, whose role in the pathogenesis of the disease might be supported by data confirming beneficial effects of caffeine from other sources, e.g. tea or cola drinks [61]. It is believed that caffeine exhibits neuroprotective effects by blocking adenosine receptors. This in turn results in higher concentrations of serotonin and acetylcholine neurotransmitters in the central nervous system $[6,53,62,67,80]$. A clinical study on Parkinson's patients demonstrated that administration of adenosine receptor antagonists alleviates disease symptoms [81]. Experimental studies on animal models revealed that caffeine stabilizes bloodbrain barrier (BBB) integrity, which contributes to brain homeostasis. The BBB disruption has been implicated in the pathogenesis of a number of neurodegenerative disorders, including dementia, AD, and PD. However, the detailed molecular mechanism of caffeine's action on BBB remains poorly understood [68]. Some studies have revealed that also the main metabolites of this substance, i.e. paraxanthine and theophylline, have similar neuroprotective properties as caffeine [69].

Also, individual conditioning, including the metabolic rate, is taken into account when analyzing the role of caffeine in the mechanism of the disease. The cytochrome P450 (CYP 1A2) enzyme is responsible for caffeine degradation, and its genotype-conditioned activity determines the metabolic rate. Carriers of the AA genotype metabolize caffeine much faster than do carriers of the AC or CC genotype [82-84]. At present, it is difficult to precisely determine the effect of that factor. In a study by Popat et al., a positive correlation between coffee intake and the risk of PD 


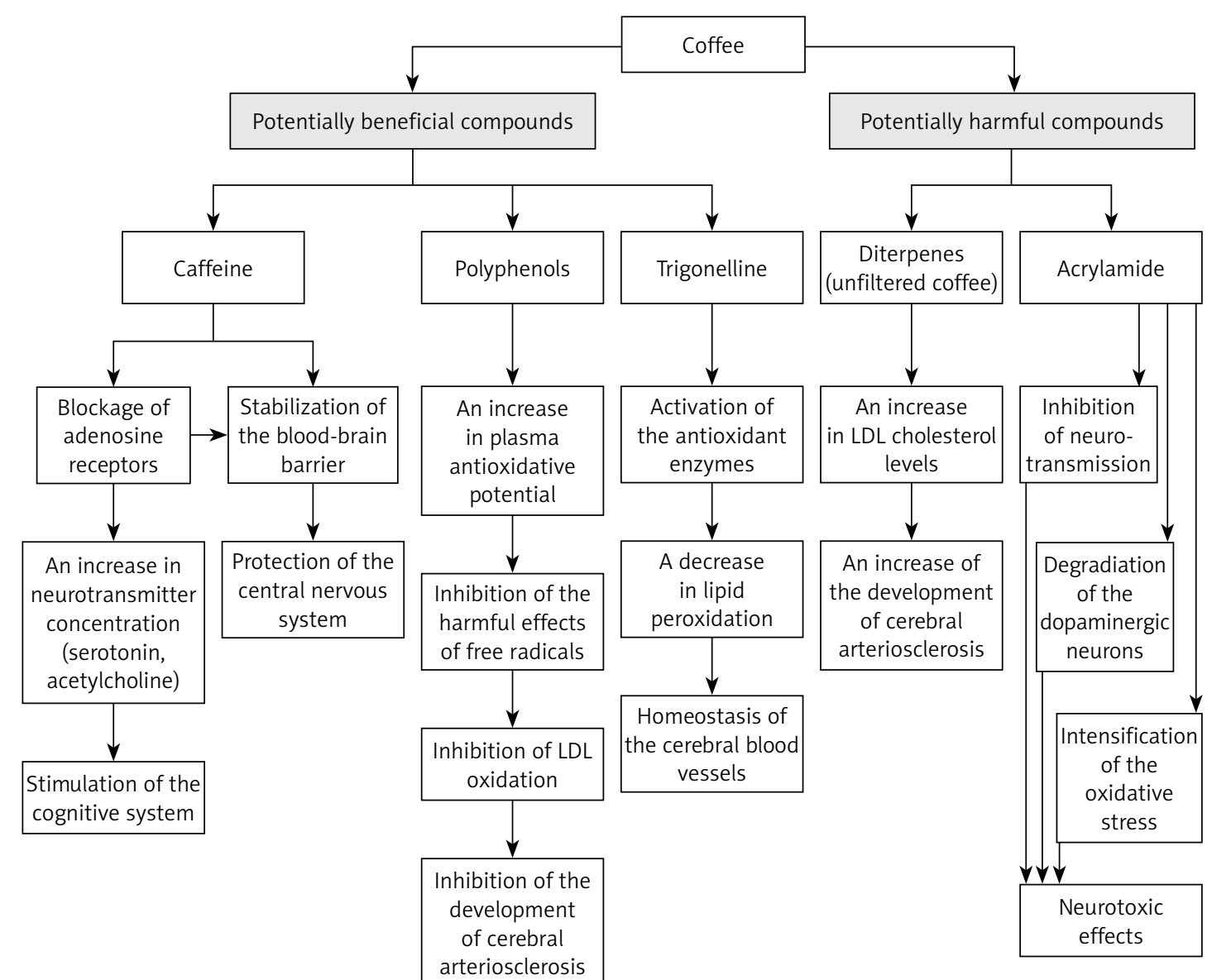

Figure 1. The possible mechanism of the impact of coffee on the risk for neurodegenerative diseases $[6,66-79]$

was stronger in slow metabolizers of caffeine [85], whereas Tan et al. found no association with metabolic rate [84]. As for the role of caffeine in the process of slowing down the development of neurodegenerative diseases, the potentially beneficial dose has not been determined, and the abovementioned studies lack more detailed data on its exact amount in the particular brews. Moreover, the dose is typically cup-dependent. A typical portion of coffee in the USA is $250 \mathrm{ml}$, whereas in Europe it is much smaller $(125-150 \mathrm{ml})$. On the other hand, American brews are weaker than those in European countries [86].

Another positive effect of coffee may be related to an improved oxidative system due to polyphenols. Oxidative stress is considered to be a promoting factor for PD $[25,68]$. Chlorogenic acid, one of the most important polyphenols to be found in coffee, has well-documented antioxidant properties and thus may inhibit the destructive effects of free radicals on neurons. The literature has suggested that neuroprotective activity of chlorogenic acid is the basis for further research on its use for therapeutic purposes [70, 75]. The amount of polyphenols in coffee depends on numerous factors, including their content in coffee beans and the method of brewing. The authors of various meta-analyses emphasize the lack of precise data about the method of brewing in the available publications, which may explain the inconsistent results $[25,52]$. Also, the method of brewing coffee affects the content of cholesterol-raising diterpenes - cafestol and kahweol. Unfiltered, boiled coffee is rich in diterpenes, whereas filtered coffee has far lower concentrations of these compounds because of their retention by the filter paper [76]. Two meta-analyses of randomized controlled trials indicated that consumption of unfiltered coffee increases serum lipid levels $[77,78]$. Some experts believe that coffee brewed without filters in fact increases the risk of dementia due to a higher serum concentration of cholesterol [39].

Coffee also contains the alkaloid trigonelline and products of its partial degradation during the roasting process - nicotinic acid and $\mathrm{N}$-methylpyridinium. All of them are bioactive constituents and have been investigated as potential neuroprotective agents. However, similarly to other coffee compounds, their exact action remains to be fully elucidated. Trigonelline is believed to have the ability to induce axonal extension in human 
neuroblastoma and thus enhance synapse formation. Moreover, it may increase the activity of the antioxidant enzymes and decrease lipid peroxidation $[66,71,79]$. Niacin (vitamin $B_{3}$ ) is involved in a multitude of intracellular processes. It plays an important role as an antioxidant in brain mitochondria, and it is considered to be a protective factor against cognitive decline. Coffee can be a source of a considerable part of the daily niacin supply for coffee drinkers [87, 88].

Positive effects of coffee consumption on the decreased risk of $A D$ may be related to lower incidence of type 2 diabetes due to the fact that insulin resistance is considered in the etiology of that disease [8]. Other factors must also be taken into account, chief among them smoking. Smokers process caffeine at a much higher rate, and that might hinder the attempts to establish a link between coffee intake and the state of cognitive functions $[2,43]$.

\section{Conclusions}

The cumulative body of evidence about lower incidence of PD and AD among coffee drinkers is substantial but not conclusive enough to prove a positive effect of coffee consumption on the development of these diseases. The current state of knowledge permits the conclusion that coffee intake does not constitute a health risk. Taking into account the fact that most people drink coffee for pleasure, because of its taste, the additional and unexpected health benefit would be an added value.

Of note, in 2015, a cup of coffee and of tea were included in the new graphic food pyramid designed by the National Food and Nutrition Institute in Warsaw [89]. The American experts are also of the opinion that moderate coffee intake may in fact become an element of a rational and healthy diet [90].

\section{Conflict of interest}

The author declares no conflict of interest.

\section{References}

1. Jarosz M, Rychlik E, Sekuła W. Diet and life expectancy in Poland between 1950 and 2012. Ann Nutr Metab 2015; 67 (Suppl 1): 134-5.

2. Bailey R, Arab L. Nutritional prevention of cognitive decline. Adv Nutr 2012; 3: 732-3.

3. Hu N, Yu JT, Tan L, Wang YL, Sun L, Tan L. Nutrition and the risk of Alzheimer's disease. Biomed Res Int 2013. 2013: 524820

4. Jóźwiak A. Dementia in the elderly. Geriatria 2008; 2 : 237-46.

5. Zieliński A. Ageing individuals and ageing populations. Przegl Epidemiol 2014; 68: 399-404.

6. Eskelinen MH, Kivipelto M. Caffeine as a protective factor in dementia and Alzheimer's disease. J Alzheimers Dis 2010; 20 (Suppl 1): 167-74.
7. Gaweł M, Potulska-Chromik A. Neurodegenerative diseases: Alzheimer's and Parkinson's disease. Postep Nauk Med 2015; 28: 468-76.

8. Kim YS, Kwak SM, Myung SK. Caffeine intake from coffee or tea and cognitive disorders: a meta-analysis of observational studies. Neuroepidemiology 2015; 44: 51-63.

9. Laitala VS, Kaprio J, Koskenvuo M, Räihä I, Rinne JO, Silventoinen K. Coffee drinking in middle age is not associated with cognitive performance in old age. Am J Clin Nutr 2009; 90: 640-6.

10. Włodarek D. Znaczenie żywienia w chorobie Parkinsona i Alzheimera (Polish). Medycyna po Dyplomie 2005; 14 146-50.

11. Chen H, Ding D, Wang J, et al. Parkinson's disease research in prospective cohort in China. Parkinson Relat Disord 2015; 21: 1200-4.

12. Flirski M, Sobow T, Kloszewska I. Behavioural genetics of Alzheimer's disease: a comprehensive review. Arch Med Sci 2011; 7: 195-210

13. Beydoun M, Beydoun H, Garnaldo A, Teel A, Zonderman A, Wang Y. Epidemiologic studies of modifiable factors associated with cognition and dementia: systematic review and meta-analysis. BMC Public Health 2014; 14: 643-7.

14. Campdelacreu J. Parkinson's disease and Alzheimer disease: environmental risk factors. Neurologia 2014; 29: 541-9.

15. Gillette Guyonnet S, Abellan Van Kan G, Andrieu S, et al. IANA task force on nutrition and cognitive decline with aging. J Nutr Health Aging 2007; 11: 132-52.

16. González-Gross M, Marcos A, Pietrzik K. Nutrition and cognitive impairment in the elderly. Br J Nutr 2001; 86: 313-21.

17. Wyka J. Nutritional factors in prevention of Alzheimer's disease. Rocz Panstw Zakl Hig 2012; 63: 135-40.

18. Bourre JM. Effects of nutrients (in food) on the structure and function of the nervous system: update on dietary requirements for brain. Part 1: micronutrients. J Nutr Health Aging 2006; 10: 377-85.

19. Bourre JM. Effects of nutrients (in food) on the structure and function of the nervous system: update on dietary requirements for brain. Part 2: macronutrients. J Nutr Health Aging 2006; 10: 386-99.

20. Del Parigi A, Panza F, Capurso C, Solfrizzi V. Nutritional factors, cognitive decline, and dementia. Brain Res Bull 2006; 69: 1-19.

21. Lindsay J, Laurin D, Verreault R, et al. Risk factors for Alzheimer's disease: a prospective analysis from the Canadian Study of Health and Aging. Am J Epidemiol 2002; 156: 445-53.

22. Przysławski J, Stelmach M. The role of nutrients in the relieve of Alzheimer disease's symptoms. Żyw Człow Metabol 2008; 4: 332-9.

23. Czajkowski P, Nazaruk J. The role of natural ingredients in protection from neurodegenerative diseases. Geriatria 2014; 8: 258-63.

24. Dochniak M, Ekiert K. Nutrition In prevention and treatment of Alzheimer's and Parkinson's disease. Piel Zdr Publ 2015; 5: 199-208.

25. Sääksjärvi K, Knekt P, Rissanen $H$, Laaksonen MA, Reunanen A, Männistö S. Prospective study of coffee consumption and risk of Parkinson's disease. Eur J Clin Nutr 2008; 62: 908-15.

26. Carman AJ, Dacks PA, Lane RF, Shineman DW, Fillit HM. Current evidence for the use of coffee and caffeine to prevent age-related cognitive decline and Alzheimer's disease. J Nutr Health Aging 2014; 18: 383-92. 
27. Lorist MM, Tops M. Caffeine, fatigue, and cognition Brain Cognition 2003; 53: 82-94.

28. Noguchi-Shinohara M, Yuki S, Dohmoto C, et al. Consumption of green tea, but not black tea or coffee, is associated with reduced risk of cognitive decline. PLos One 2014; 9: e96013.

29. van Gelder BM, Buijsse B, Tijhuis M, et al. Coffee consumption is inversely associated with cognitive decline in elderly European men: the FINE Study. Eur J Clin Nutr 2007; 61: 226-32.

30. Eskelinen MH, Ngandu T, Tuomilehto J, Soininen H, Kivipelto $M$. Midlife coffee and tea drinking and the risk of late-life dementia: a population-based CAIDE study. J Alzheimers Dis 2009; 16: 85-91.

31. Ritchie K, Carriére I, de Mendonca A, et al. The neuroprotective effects of caffeine: a prospective population study (The Three City Study). Neurology 2007; 69: 536-45.

32. Postuma RB, Lang AE, Munhoz RP, et al. Caffeine for treatment of Parkinson disease: a randomized controlled trial. Neurology 2012; 79: 651-8.

33. Wichowicz H. Zaburzenia psychiczne towarzyszące chorobie Parkinsona [Polish]. Psych Prakt Klin 2009; 2: 1-14

34. Zlokovic BV. Vascular disorder in Alzheimer's disease: role in pathogenesis of dementia and therapeutic targets. Adv Drug Deliv Rev 2002; 54: 1553-9.

35. de la Torre. Alzheimer disease as a vascular disorder. Nosological evidence. Stroke 2002; 33: 1152-62.

36. Khan A. Small vessel disease. The Journal of Quality Research in Dementia 2008, www.alzheimers.org.uk/site/ scripts/documents_info.php?documentID $=743 \&$ pageNumber $=6$

37. Nakaguchi H, Matsuno A, Okubo T, Hoya K. Relationship between silent brain infarction and amount of daily coffee consumption in middle age. J Stroke Cerebrovasc Dis 2016; 25: 1678-82.

38. Larsson SC, Orsini N. Coffee consumption and risk of stroke. A dose-response meta-analysis of prospective studies. Am J Epidemiol 2011; 174: 993-1001.

39. Mirza SS, Tiemeier H, de Bruijn RF, et al. Coffee consumption and incident dementia. Eur J Epidemiol 2014, 29: 735-41.

40. van Boxtel MP, Schmitt JA, Bosma H, Jolles J. The effects of habitual caffeine use on cognitive change: a longitudinal perspective. Pharmacol Biochem Behav 2003; 75: 921-7.

41. Ng TP, Feng L, Niti M, Kua EH, Yap KB. Tea consumption and cognitive impairment and decline in older Chinese adults. Am J Clin Nutr 2008; 88: 224-31.

42. Solfrizzi V, Panza F, Imbimbo BP, et al. Coffee consumption habits and the risk of mild cognitive impairment: the Italian Longitudinal Study on Aging. J Alzheimers Dis 2015; 47: 889-99.

43. Santos C, Costa J, Santos J, Vaz-Carneiro A, Lunet N. Caffeine intake and dementia: systematic review and meta-analysis. J Alzheimers Dis 2010; 20 (Suppl 1): 187-204.

44. Arab L, Khan F, Lam H. Epidemiologic evidence of a relationship between tea, coffee, or caffeine consumption and cognitive decline. Adv Nutr 2013; 4: 115-22.

45. Vassar R. BACE1: the beta-secretase enzyme in Alzheimer's disease. J Mol Neurosci 2004; 23: 105-14.

46. Barcikowska M. Biomarkery, neuroobrazowanie i poszukiwanie nowych możliwości terapeutycznych w chorobie Alzheimera [Polish]. Medycyna po Dyplomie 2005; 14: 93-104.

47. Arendash GW, Cao C. Caffeine and coffee as therapeutics against Alzheimer's disease. J Alzheimers Dis 2010; 20 (Suppl): 117-26.
48. Barranco Quintana JL, Allam MF, Serrano Del Castillo A, Fernández-Crehuet Navajas R. Alzheimer's disease and coffee: a quantitative review. Neurol Res 2007; 29: 91-5.

49. Xu W, Tan L, Wang HF, et al. Meta-analysis of modifiable risk factors for Alzheimer's disease. J Neurol Neurosurg Psychiatry 2015; 86: 1299-306.

50. Jarosz M, Wierzejska R, Siuba M. Maternal caffeine intake and its effect on pregnancy outcomes. Eur J Obstet Gynecol Reprod Biol 2012; 160: 156-60.

51. de Lau LM, Breteler MB. Epidemiology of Parkinson's disease. Lancet Neurol 2006; 5: 525-35.

52. Qi H, Li S. Dose-response meta-analysis on coffee, tea and caffeine consumption with risk of Parkinson's disease. Geriatr Gerontol Int 2014; 14: 430-9.

53. Schwarzschild MA. Caffeine in Parkinson disease: better for cruise control than snooze patrol? Neurology 2012; 79: 616-8.

54. Ascherio A, Weisskopf M, O’Reilly E, et al. Coffee consumption, gender and Parkinson's disease mortality in the cancer prevention study II cohort: the modifying effects of estrogen. Am J Epidemiol 2004; 160: 977-84.

55. Ross GW, Abbott RD, Petrovitch H, et al. Association of coffee and caffeine intake with the risk of Parkinson disease. JAMA 2000; 283: 2674-9.

56. Benedetti MD, Bower JH, Maraganore DM, et al. Smoking, alcohol, and coffee consumption preceding Parkinson's disease: a case-control study. Neurology 2000; 55 : 1350-8.

57. Morano A, Jiménez-Jiménez FJ, Molina JA, Antolin MA. Risk-factors for Parkinson's disease: case-contrl study in the province of Cáceres, Spain. Acta Neurol Scand 1994; 89: 164-70.

58. Checkoway H, Powers K, Smith-Weller T, Franklin GM, Longstreth WT, Swanson PD. Parkinson's disease risk associated with cigarette smoking, alcohol consumption, and caffeine intake. Am J Epidemiol 2002; 155: 732-8.

59. Jiménez-Jiménez FJ, Mateo D, Giménez-Roldan S. Premorbid smoking, alcohol consumption, and coffee drinking habits in Parkinson's disease: a case-control study. Mov Disord 1992; 7: 339-44.

60. Louis ED, Luchsinger JA, Tang MX, Mayeux R. Parkinsonian signs in older people: prevalence and associations with smoking and coffee. Neurology 2003; 61: 24-8.

61. Hernán MA, Takkouche B, Caamaño-Isorna F, Gestal-Otero JJ. A meta-analysis of coffee drinking, cigarette smoking, and the risk of Parkinson's disease. Ann Neurol 2002; 52: 276-84.

62. Higdon JV, Frei B. Coffee and health: a review of recent human research. Crit Rev Food Sci Nutr 2006; 46: 101-23.

63. Liebeskind DS, Sanossian N, Fu KA, Wang HJ, Arab L. The coffee paradox in stroke: increased consumption linked with fewer strokes. Nutr Neurosci 2015 in press; doi: http://dx.doi.org/10.1179/1476830515Y.0000000035.

64. Costa J, Lunet N, Santos C, Santos J, Vaz-Carneiro A. Caffeine exposure and the risk of Parkinson's disease: a systematic review and meta-analysis of observational studies. J Alzheimers Dis 2010; 20 (Suppl): 221-38.

65. Mojska H, Gielecińska I. Studies of acrylamide level in coffee and coffee substitutes: influence of row material and manufacturing conditions. Rocz Panstw Zakl Hig 2013; 64: 173-81.

66. Makowska J, Szczesny D, Lichucka A, Giełdoń A, Chmurzyński L, Kaliszan R. Preliminary studies on trigonelline as potential anti-Alzheimer disease agent: determination by hydrophilic interaction liquid chromatography and modeling of interactions with beta-amyloid. J Chromatogr B 2014; 968: 101-4. 
67. Prediger RD. Effects of caffeine in Parkinson's disease: from neuroprotection to the management of motor and non-motor symptoms. J Alzheimers Dis 2010; 20 (Suppl): 205-20.

68. Chen X, Lan X, Roche I, Liu R, Geiger JD. Caffeine protects against MPTP-induced blood-brain barrier dysfunction in mouse striatum. J Neurochem 2008; 107: 1147-57.

69. Xu K, Xu YH, Chen JF, Schwarzschild MA. Neuroprotection by caffeine: time course and role of its metabolites in the MPTP model of Parkinson disease. Neuroscience 2010; 167: 475-81.

70. Liang N, Kitts DD. Role of chlorogenic acids in controlling oxidative and inflammatory stress conditions. Nutrients 2015; 8: pii: E16.

71. Liang N, Kitts DD. Antioxidant property of coffee components: assessment of methods that define mechanisms of action. Molecules 2014; 19: 19180-208.

72. Lopachin RM, Gavin T. Acrylamide-induced nerve terminal damage: relevance to neurotoxic and neurodegenerative mechanisms. J Agric Food Chem 2008; 56 5994-6003.

73. Erkekoglu P, Baydar T. Acrylamide neurotoxicity. Nutr Neurosci 2014; 17: 49-57.

74. Li J, Li D, Yang Y, Xu T, Li P, He D. Acrylamide induces locomotor defects and degeneration of dopamine neurons in Caenorhabditis elegans. J Appl Toxicol 2016; 36: 60-7.

75. Agudelo-Ochoa GM, Pulgarín-Zapata IC, Velásquez-Rodriguez CM, et al. Coffee consumption increases the antioxidant capacity of plasma and has no effect on the lipid profile or vascular function in healthy adults in a randomized controlled trial. J Nutr 2016; 146: 524-31.

76. Gross G, Jaccaud E, Huggett AC. Analysis of the content of the diterpenes cafestol and kahweol in coffee brews. Food Chem Toxicol 1997; 35: 547-54.

77. Cai L, Ma D, Zhang Y, Liu Z, Wang P. The effect of coffee consumption on serum lipids: a meta-analysis of randomized controlled trials. Eur J Clin Nutr 2012; 66: 872-7.

78. Jee SH, He J, Appel LJ, Whelton PK, Suh I, Klag MJ. Coffee consumption and serum lipids: a meta-analysis of randomized controlled clinical trials. Am J Epidemiol 2001; 153: 353-62.

79. Tohda C, Nakamura N, Komatsu K, Hattori M. Trigonelline-induced neurite outgrowth in human neuroblastoma SK-N-SH cells. Biol Pharm Bull 1999; 22: 679-82.

80. Wierzejska R. Caffeine - common ingredients in a diet and its influence on human health. Rocz Panstw Zak Hig 2012; 63: 141-7.

81. Bara-Jimenez W, Sherzai A, Dimitrova T, et al. Adenosine $A(2 A)$ receptor antagonist treatment of Parkinson's disease. Neurology 2003; 61: 293-6.

82. Landi MT, Sinha R, Lang NP, Kadlubar FF. Human cytochrome P4501A2. IARC Sci Publ 1999; 148: 173-95.

83. Mostofsky E, Rice MS, Levitan EB, Mittleman MA. Habitual coffee consumption and risk of heart failure: a dose-response meta-analysis. Circ Heart Fail 2012; 5: 401-5.

84. Tan EK, Chua E, Fook-Chong SM, et al. Association between caffeine intake and risk of Parkinson's disease among fast and slow metabolizers. Pharmacogenet Genomics 2007; 17: 1001-5.

85. Popat RA, Van Den Eeden SK, Tanner CM, et al. Coffee, ADORA2A, and CYP1A2: the caffeine connection in Parkinson's disease. Eur J Neurol 2011; 18: 756-65.

86. van Dam RM, Hu FB. Coffee consumption and risk of type 2 diabetes. A systematic review. JAMA 2005; 294 97-104.
87. Morris MC, Schneider JA, Tangney CC. Thoughts on B-vitamins and dementia. J Alzheimers Dis 2006; 9: 429-33. 88. Rennie G, Chen AC, Dhillon H, Vardy J, Damian DL. Nic otinamide and neurocognitive function. Nutr Neurosci 2015; 18: 193-200.

89. The graphic food pyramids. National Food and Nutrition Institute, Warsaw, Poland http://www.izz.waw.pl

90. Scientific Report of the 2015 Dietary Guidelines Advisory Committee. http://health.gov/dietaryguidelines/ 2015-scientific-report/. 